\title{
Psychometric properties of the STAI-Y scales and normative data in an Italian elderly population
}

\author{
Ciro Rosario llardi ${ }^{1} \cdot$ Nadia Gamboz $^{2} \cdot$ Alessandro lavarone $^{3}$ (D) Sergio Chieffi ${ }^{4}$ Maria Antonella Brandimonte ${ }^{2}$
}

Received: 4 December 2020 / Accepted: 13 February 2021 / Published online: 17 March 2021

(c) The Author(s), under exclusive licence to Springer Nature Switzerland AG part of Springer Nature 2021

\begin{abstract}
Background Early detection of anxiety symptoms in older people is capital as it may be linked to increased physical/functional disabilities, onset and progression of neurodegenerative disorders, and poor cognitive functioning. Nonetheless, there is a paucity of psychometrically validated anxiety measures in the elderly.

Aims This study aimed at assessing the psychometric properties of the State-Trait Anxiety Inventory-Form Y (STAI-Y) and providing the first normative data for the Italian elderly population.

Methods The sample included 361 individuals aged 65-94. All subjects underwent the Mini-Mental State Examination (MMSE), the Geriatric Depression Scale (GDS), and the state (S-Anxiety) and trait anxiety (T-anxiety) scales of the STAI-Y. Results The S-Anxiety and T-Anxiety scales showed reliable internal consistency and, overall, good item characteristics. Divergent validity was "apparently" threatened, with S-Anxiety scale correlating with MMSE and GDS, and T-Anxiety scale only with GDS. The principal component analysis revealed a three-factor solution for both scales, i.e., presence and absence of state (or trait) anxiety, and performance anxiety. Since no effect of sociodemographic variables was found, unadjusted cutoffs were provided.

Conclusions Although some questions on the psychometric properties of the STAI-Y remain unanswered, this normative study can help clinicians and researchers to monitor anxiety levels in the Italian elderly population.
\end{abstract}

Keywords State-trait anxiety inventory $\cdot$ Elderly $\cdot$ Psychometric properties $\cdot$ Normative study $\cdot$ Italian population

\section{Introduction}

In the present paper, we focus on a frequent symptom among the elderly: anxiety. Anxiety disorders affect from 3 to $15 \%$ of the elderly [1]; sub-threshold anxiety symptoms are even more frequent, with prevalence ranging from 15 to $52 \%$ [2]. There are several reasons why clinicians and researchers need to pay close attention to anxiety symptoms in the elderly.

Alessandro Iavarone

aleiavarone@gmail.com

1 Department of Psychology, University of Campania "Luigi Vanvitelli”, Caserta, Italy

2 Laboratory of Experimental Psychology, Suor Orsola Benincasa University, Naples, Italy

3 Neurological Unit, CTO Hospital, AORN “Ospedali dei Colli”, Naples, Italy

4 Department of Experimental Medicine, University of Campania “Luigi Vanvitelli”, Naples, Italy
First, anxiety disorders, as well as sub-threshold anxiety symptoms, are associated with a physical disability, higher risk of adverse outcomes after myocardial infarction [3, 4], functional impairment, poorer quality of life, sleep disorders, and increased mortality [5].

Second, anxiety appears to be a risk factor for the development of age-related neurocognitive disorders. Higher levels of anxiety were found to be associated with greater cognitive decline over time [6], with cognitive deficits in Parkinson's disease [7], with increased risk of developing dementia [8] and of converting from mild cognitive impairment to dementia [9].

Last but not least, anxiety negatively affects cognitive performance [10]. According to the attentional control theory (ACT) [11], anxiety enhances the influence of the stimulus-driven attentional system over the more efficient goal-driven system; as a result, the susceptibility to threatrelated information increases, hence hindering task performance. Some studies showed that, in community-dwelling elderly, sub-threshold anxiety affected executive functions 
[12] and episodic memory [1]. Other studies, however, found no relationship between anxiety and cognitive performance [13].

Still, it is relevant to stress that any effect of anxiety on cognitive performance is highly relevant for both clinical- and research-related assessment involving older adults [14]. Indeed, anxiety may confound testing results and the physiological age-related cognitive decline may be exacerbated in anxious individuals.

The above overview suggests how important is detecting anxiety in the elderly. Self-report measures, such as the Form-Y of the State-Trait Anxiety Inventory (STAI-Y) [15], the Beck Anxiety Inventory (BAI) [16], and the Taylor Manifest Anxiety Scale (TMAS) [17] are some of the most commonly used tools for quantifying general anxiety, the majority of which have been, however, validated in younger populations. Among these, the STAI-Y may be a good candidate to explore anxiety in older adults. STAI-Y norms and psychometric data for older people are currently available only in the French population $[18,19]$. No normative data exist for the Italian population. The present paper is an attempt to fill this gap.

The employment of the STAI-Y for measuring anxiety in the elderly may be convenient for different reasons. It showed good psychometric properties in samples of both younger [15] and older adults [20, 21]. In addition, since the STAI-Y is less oriented towards somatic components of anxiety (e.g., pain, difficulty in breathing, sleep disorders) than other widely used scales such as the BAI and TMAS, the risk of overlap between medical and psychological determinants of anxiety is lower [22]. Moreover, several versions of the STAI-Y are available in different languages; this makes it useful for investigating anxiety across cultures and, after collecting normative data from elderly cohorts, also across the life span. Finally, as the STAI-Y is the only anxiety scale allowing for a clear separation between state and trait anxiety [15, 20,22], it is particularly suitable for detecting transitory rises of anxiety, which may bias clinical and experimental outcomes in assessment contexts involving elderly.

One important weakness of the STAI-Y concerns its limited construct validity, as indexed by the weak-to-moderate correlation (ranging from 0.16 to 0.57 ) with measures of worry [23]. Even so, the STAI-Y is the best-known and most widely used self-report questionnaire to assess anxiety in research and clinical practice [24].

The aims of the present study are therefore to assess the psychometric properties of the STAI-Y and provide normative data for the Italian elderly population. To the best of our knowledge, this is the first normative Italian study addressing this issue.

\section{Methods}

\section{Subjects and procedure}

A total of 398 community-dwelling Italian older adults (226 females) from the Campania region participated in this study as volunteers. All subjects performed the MiniMental State Examination (MMSE) [25], the Geriatric Depression Scale (GDS) [26], and the Italian version of the STAI-Y [27].

The STAI-Y is a self-report questionnaire consisting of two 20-item scales providing separate measures of state and trait anxiety (S-Anxiety and T-Anxiety, respectively). S-Anxiety is a transitory response to an event perceived as adverse, characterized by feelings of tension, apprehension, nervousness, and worry. T-Anxiety is, instead, a more stable predisposition to perceive stressful situations as dangerous or threatening [15]. Consequently, the S-Anxiety scale includes twenty items evaluating how the subject feels "right now, at this moment", while the T-Anxiety scale includes twenty items evaluating how the subject feels "generally". On a 4-point Likert scale (1-4), a score equal to 4 indicates the presence of a higher level of anxiety for ten S-Anxiety (3, 4, 6, 7, 9, 12, 13, 14, $17,18)$ and eleven T-Anxiety items $(2,4,5,8,9,11,12$, $15,17,18,20)$. As for the remaining items, the scoring weights are reversed. The total score for both scales ranges from 20 to 80, with higher scores indicating more severe anxiety [15].

Inclusion criteria were as follows: age equal or greater than 65 years old, at least 3 years of formal education, adjusted MMSE score higher than the normative cutoff value, and completion of the whole testing protocol. Exclusion criteria were as follows: neurocognitive or psychiatric disorders (e.g., mild cognitive impairment, dementia, Parkinson's disease, schizophrenia), history of epilepsy, transient ischemic attack, stroke, or head injury, evidence of serious health condition, history of alcohol or substance abuse, and intake of psychotropic drugs. To prevent a "hyper-normality bias", any subject with well-pharmacologically compensated diseases (e.g., hypertension, diabetes) was not excluded [28].

According to the exclusion criteria, data from 37 subjects were removed. The final normative sample included 361 individuals. The distribution of sociodemographic variables is reported in Table 1. Descriptive statistics on demographic and clinical variables are summarized in Table 2.

\section{Statistical analyses}

To detect potential effects of the sociodemographic variables on the S-Anxiety and T-Anxiety scales, we performed 
Table 1 Distribution of sociodemographic characteristics of the normative sample

\begin{tabular}{lllllllll}
\hline $\begin{array}{l}\text { Education } \\
\text { (years) }\end{array}$ & Sex & \multicolumn{2}{l}{ Age (years) } & \\
\cline { 2 - 7 } & & $65-69$ & $70-74$ & $75-79$ & $80-84$ & $85-89$ & $90-94$ & Total \\
\hline $3-5$ & Male & 29 & 12 & 15 & 13 & 4 & 1 & 74 \\
& Female & 36 & 40 & 16 & 20 & 12 & 4 & 128 \\
$6-8$ & Male & 32 & 9 & 6 & 1 & 2 & - & 50 \\
& Female & 29 & 7 & 3 & - & - & - & 39 \\
$9-13$ & Male & 15 & 8 & 2 & 1 & - & - & 26 \\
& Female & 12 & 1 & 2 & - & 1 & - & 16 \\
$>13$ & Male & 11 & 1 & - & - & - & - & 12 \\
& Female & 9 & 3 & 2 & 1 & 1 & - & 16 \\
Total & & 173 & 81 & 46 & 36 & 20 & 5 & 361 \\
\hline
\end{tabular}

Table 2 Descriptive statistics

\begin{tabular}{llll}
\hline Demographic and clinical variables & $\begin{array}{l}\text { Subjects included } \\
(n=361)\end{array}$ & $\begin{array}{l}\text { Subjects excluded } \\
(n=37)\end{array}$ & $p$ value $\left(\chi^{2} / U\right)$ \\
\hline Sex (female/male) & $199 / 162$ & $27 / 10$ & $<0.05$ \\
Age (years), mean (SD) & $71.75(7.06)$ & $70.97(5.47)$ & 0.93 \\
Education (years), mean (SD) & $7.01(4.06)$ & $6.92(3.39)$ & 0.68 \\
MMSE raw score, mean (SD) & $28.37(1.55)$ & $25.89(3.85)$ & $<0.01$ \\
GDS, mean (SD) & $5.23(5.03)$ & $6.89(5.70)$ & $<0.05$ \\
S-Anxiety scale, mean (SD) & $37.08(11.46)$ & $41.43(13.72)$ & 0.06 \\
T-Anxiety scale, mean (SD) & $37.19(11.50)$ & $40.22(15.71)$ & 0.45 \\
\hline
\end{tabular}

MMSE Mini-Mental State Examination, GDS Geriatric Depression Scale, $U$ Mann-Whitney $U$ Test

two separate simultaneous multiple linear regression analyses assuming the total S-Anxiety (and T-Anxiety) score as dependent variable and sex, age, and education as predictors. If a significant contribution to the scale's variance was found for at least one of the variables under examination, the correction procedure proposed by Spinnler and Tognoni [29] would have been applied (see also Garofalo et al. [28]).

Item characteristics, reliability, and scaling assumptions were tested using the corrected Pearson's item-total correlation. An item-total correlation $>30$ was deemed acceptable [30].

As made for regression analysis, we performed two separate principal component analyses (PCAs) with Varimax orthogonal rotation to approximate the factorial solutions for both the S-Anxiety and T-Anxiety scales. The number of factors to be extracted was determined following the Mineigen criterion (eigenvalues $>1$ [31]) or inspecting the scree plot [32]. Furthermore, Spearman's correlation analysis ( $\left.r_{\text {rho }}\right)$ was used to quantify the association between items, or factors, and total score, and to test divergent validity. The Cohen's conventions were used to interpret the effect size (weak, $r_{\text {rho }}<0.30$; moderate, $r_{\text {rho }}=0.30-0.50 ;$ strong, $\left.r_{\text {rho }}>0.50\right)$. Internal consistency was computed using Cronbach's alpha coefficient.
Since both scales were constructed so that higher scores reflect more severe anxiety, cutoffs were fixed at the nonparametric outer tolerance limit on the 95th centile, with 95\% confidence interval [28]. Finally, we quantified the "uncertainty" associated with our normative data by applying Crawford and Garthwaite's procedure [33]. Statistical analyses were performed by IBM SPSS Statistics (v. 26), STATA (v. 15), and QUAND.exe programs.

\section{Results}

We ran a preliminary analysis to test the univariate normality of S-Anxiety and T-Anxiety total scores. Skewness and kurtosis indexes were examined. For each scale, the skewness and kurtosis values were in the acceptable range $(-1.0$ and +1.0$)$, thus suggesting the absence of appreciable deviations from normality [34]. As shown in Table 2, the mean S-Anxiety score was $37.08(\mathrm{SD}=11.46$, range $=20-76 ; n=361)$ and the mean $\mathrm{T}$-Anxiety score was $37.19(\mathrm{SD}=11.50$, range $=22-84 ; n=361)$. No difference was found between men and women on the age variable $\left(\chi^{2}(5)=7.739, p=0.17\right)$. Conversely, a significant difference on the education variable was observed $\left(\chi^{2}(3)=15.114\right.$, 
$p<0.001, \varphi=0.20$ ), i.e., a larger number of lowly educated women.

About the regression analysis, we found no effect of sex, age, or education on S-Anxiety score $\left(R^{2}=0.01, F(3\right.$, $357)=1.311, p=0.27 ; B_{\mathrm{Sex}}=0.49, \mathrm{SE}=1.22 ; p=0.69$; $B_{\mathrm{Age}}=0.02, \mathrm{SE}=0.09, p=0.86 ; B_{\text {Education }}=-0.27$, $\mathrm{SE}=0.16, p=0.09)$. Similarly, T-Anxiety score was unaffected by sociodemographic variables $\left(R^{2}=0.002, F(3\right.$, $357)=0.269, p=0.85 ; B_{\mathrm{Sex}}=-0.72, \mathrm{SE}=1.23 ; p=0.56$; $B_{\mathrm{Age}}=-0.06, \mathrm{SE}=0.09, p=0.53 ; B_{\text {Education }}=-0.02$, $\mathrm{SE}=0.16, p=0.88)$. Consequently, no adjustment of raw scores was required.

Most of the items of the S-Anxiety scale showed a significant moderate (items $1,7,16-19 ; r_{\text {rho }}$ range $=0.38-0.50$, $p_{\mathrm{s}}<0.001$ ) to strong correlation (items $2-6,8-12,14,15$, $20 ; r_{\text {rho }}$ range $\left.=0.51-0.69, p_{\mathrm{s}}<0.001\right)$ with the total score, and a more than acceptable level of discrimination (itemtotal correlations, range $=0.38-0.70$ ). Only item 13 was weakly correlated to the total score $\left(r_{\text {rho }}=0.19, p<0.001\right)$ and had a poor level of discrimination (item-total correlation $=0.16$ ). As for the T-Anxiety scale, all items showed a significant moderate (items $1,4,9,10,12,16-20 ; r_{\text {rho }}$ range $=0.35-0.43, p_{\mathrm{s}}<0.001$ ) to strong correlation (items 2 , $3,5-8,11,13-15 ; r_{\text {rho }}$ range $=0.51-0.64$, all $\left.p_{\mathrm{s}}<0.001\right)$ with the total score, and a good level of discrimination (item-total correlation, range $=0.37-0.69$ ), with the exception of item 20 (item-total correlation $=0.23)($ see Online Resource 1$)$. Both questionnaires demonstrated reliable internal consistency as shown by a Cronbach's $\alpha$ of 0.90 .

Divergent validity was measured by correlating S-Anxiety and T-Anxiety scores with MMSE and GDS. The S-Anxiety scale showed a small linear association with MMSE $\left(r_{\text {rho }}=-0.13, p<0.05\right)$ and GDS $\left(r_{\text {rho }}=0.23, p<0.001\right)$. Conversely, the T-Anxiety scale showed no correlation with $\operatorname{MMSE}\left(r_{\text {rho }}=-0.09, p=0.07\right)$, and a moderate correlation with GDS $\left(r_{\text {rho }}=0.48, p<0.001\right)$.

Using the Mineigen criterion (eigenvalues $>1$ ), the PCA suggested a three-factor solution for the S-Anxiety scale, and a four-factor solution for the T-Anxiety scale (with one factor including only one item, i.e., item 20). From inspection of the scree plots, a three-factor solution was confirmed for the S-Anxiety scale; conversely, for the T-Anxiety scale, a three-factor model provided the best fit. The three-factor models presented a clear and parsimonious structure, with components showing strong loadings (all $>0.50$ ) and a minimal number of overlapping items between factors (i.e., item 19 of the T-Anxiety scale loading $\geq 0.50$ on both factor 1 and 2). Table 3 shows the factorial structures of both scales.

The cutoffs were fixed at the non-parametric outer tolerance limits on the 95th centile (95\% confidence interval). As for the S-Anxiety scale, the cutoff was 67.13 and should guarantee higher specificity. A lower cutoff score, e.g., the external tolerance limit on the 90th centile, could ensure higher sensitivity (90th centile cutoff $=61$ ). As for the T-Anxiety scale, the cutoffs calculated on the 90th and 95th centiles were 54.19 and 66.25 , respectively.

The QUAND.exe program (Quantifying the Uncertainty Attached to Normative Data) was used to test the robustness/ fallibility of our normative data [33]. It requires the entry of the mean and SD of the normative sample, the sample size, and the minimum and maximum test scores. The software converts each raw score into the relative $z$-score $(95 \%$ confidence limits). We performed two separate analyses for each scale. The analysis' output is available in Online Resource 2. From a statistical standpoint, confidence intervals should become wider as the difference between the raw score and the normative sample mean increases. As a consequence, wider intervals for scores close to the mean suggest the presence of measurement errors [33]. The results of Crawford and Garthwaite's test supported the robustness of our normative data since confidence intervals were tighter for scores close to the mean and became, instead, wider for scores above the normative cutoff.

\section{Discussion}

The present paper aimed at assessing the psychometric properties of the STAI-Y and providing the first normative data for Italian elderly people.

In line with previous studies $[18,19,21]$, both the S-Anxiety and T-Anxiety scales demonstrated strong internal consistency. Indeed, almost all items showed a good discriminant power apart from item 13 of the S-Anxiety scale and item 20 of the T-Anxiety scale. These two items, therefore, seem not very appropriate for screening anxiety in the Italian elderly.

Both the S-anxiety and T-Anxiety scales showed a significant positive linear association with GDS. The well-known partial overlap between symptoms of anxiety and depression (e.g., sleep disturbance, fatigue, difficulty concentrating) [35] likely accounts for this result. Symptoms of anxiety and depression are frequently comorbid both in young [36] and elderly populations [37]. Whether anxiety and depression are discrete disorders or belong to the same nosographic category is still a matter of intense debate [38].

The S-Anxiety scale, moreover, correlated weakly, and negatively, with MMSE, whereas the T-Anxiety scale did not. Note that the neuropsychological setting is a potentially state-anxiety-inducing context per se, which can generate evaluation apprehension: since the subject is conscious of being under assessment, she/he tries to appear as "normal" as possible in response to the current canons of social desirability. Therefore, the pre-test and post-test evaluation of the S-Anxiety could help clinicians, 
Table 3 Rotated component matrix of S-Anxiety and

T-Anxiety scales

\begin{tabular}{|c|c|c|c|}
\hline Items & Factor 1 & Factor 2 & Factor 3 \\
\hline \multicolumn{4}{|l|}{ S-Anxiety scale } \\
\hline 2. I feel secure & 0.802 & 0.100 & 0.150 \\
\hline 20. I feel pleasant & 0.763 & 0.117 & 0.318 \\
\hline 19. I feel steady & 0.755 & 0.048 & 0.050 \\
\hline 5. I feel at ease & 0.740 & 0.107 & 0.335 \\
\hline 11. I feel self-confident & 0.728 & 0.165 & 0.262 \\
\hline 8. I feel satisfied & 0.679 & 0.088 & 0.292 \\
\hline 16. I feel content & 0.625 & 0.115 & 0.318 \\
\hline 1. I feel calm & 0.618 & 0.011 & 0.271 \\
\hline 9. I feel frightened & -0.067 & 0.866 & 0.113 \\
\hline 10. I feel comfortable & 0.121 & 0.847 & -0.085 \\
\hline 14. I feel indecisive & 0.089 & 0.828 & 0.233 \\
\hline 15. I am relaxed & 0.305 & 0.825 & -0.102 \\
\hline 12. I feel nervous & 0.098 & 0.820 & 0.155 \\
\hline 18. I feel confused & 0.295 & 0.196 & 0.647 \\
\hline 13. I am jittery & 0.012 & -0.232 & 0.611 \\
\hline 7. I am presently worrying over possible misfortunes & 0.337 & 0.135 & 0.603 \\
\hline 17. I am worried & 0.277 & -0.004 & 0.593 \\
\hline 3. I am tense & 0.471 & 0.125 & 0.588 \\
\hline 4. I feel strained & 0.386 & 0.222 & 0.569 \\
\hline 6. I feel upset & 0.415 & 0.226 & 0.561 \\
\hline Variance explained (\%) & 38.03 & 15.87 & 6.31 \\
\hline Correlation $\left(r_{\text {rho }}\right)$ with total score & $0.46^{*}$ & $0.73 *$ & $0.33 *$ \\
\hline Cronbach's $\alpha$ & 0.90 & 0.90 & 0.80 \\
\hline \multicolumn{4}{|l|}{ T-Anxiety scale } \\
\hline 18. I take disappointments so keenly that I can't put them out of my mind & 0.713 & 0.074 & 0.157 \\
\hline 12. I lack self-confidence & 0.701 & 0.075 & 0.038 \\
\hline 4. I wish I could be as happy as others seem to be & 0.697 & -0.067 & 0.157 \\
\hline 9. I worry too much over something that really doesn't matter & 0.686 & -0.094 & 0.216 \\
\hline 10. I am happy & 0.657 & 0.352 & -0.071 \\
\hline 16. I am content & 0.619 & 0.441 & -0.113 \\
\hline 17. Some unimportant thought runs through my mind and bothers me & 0.618 & 0.105 & 0.150 \\
\hline 1. I feel pleasant & 0.598 & 0.507 & -0.118 \\
\hline 19. I am a steady person ${ }^{a}$ & 0.513 & 0.502 & -0.087 \\
\hline 14. I make decisions easily & 0.132 & 0.777 & 0.311 \\
\hline 6. I feel rested & 0.069 & 0.711 & 0.285 \\
\hline 13. I feel secure & 0.086 & 0.681 & 0.429 \\
\hline 3. I feel satisfied with myself & 0.161 & 0.638 & 0.438 \\
\hline 7. I am "calm, cool, and collected" & -0.002 & 0.614 & 0.376 \\
\hline 15. I feel inadequate & 0.104 & 0.126 & 0.762 \\
\hline 5. I feel like a failure & -0.020 & 0.341 & 0.751 \\
\hline 8. I feel that difficulties are piling up so that I cannot overcome them & 0.266 & 0.354 & 0.679 \\
\hline 2. I feel nervous and restless & 0.219 & 0.300 & 0.678 \\
\hline 11. I have disturbing thoughts & 0.247 & 0.374 & 0.677 \\
\hline $\begin{array}{l}\text { 20. I get in a state of tension or turmoil as I think over my recent concerns and } \\
\text { interests }\end{array}$ & -0.081 & -0.001 & 0.566 \\
\hline Variance explained (\%) & 35.48 & 15.15 & 7.26 \\
\hline Correlation $\left(r_{\text {rho }}\right)$ with total score & $0.45^{*}$ & $0.58^{*}$ & $0.52 *$ \\
\hline Cronbach's $\alpha$ & 0.84 & 0.86 & 0.84 \\
\hline
\end{tabular}

Major loading $>0.50$ for each item are displayed in bold

$* p<.001$

${ }^{\text {a Item }} 19$ (T-Anxiety) loaded on two components with a similar extent and was not assigned to any specific factor 
as well as researchers, to control this confounded variable for increasing reliability of diagnosis and experimental results.

The PCA identified a clear and parsimonious threefactor structure for both the S-Anxiety and T-Anxiety scales. About the former, Factor 1 included items reflecting the absence of state anxiety (e.g., self-confidence, satisfaction, psychological well-being), Factor 2 included items likely referring to performance anxiety, i.e., fear of performing poorly a specific task (e.g., nervousness, tension, hesitation), and Factor 3 included items reflecting the presence of state anxiety (e.g., agitation, confusion, concern, worry). About the latter, Factor 1 included items reflecting the presence of trait anxiety (e.g., unhappiness, worry, disappointment, rumination), Factor 2 included items reflecting the absence of trait anxiety (e.g., selfconfidence, safety), and Factor 3 included items likely referring to performance anxiety (e.g., poor resilience, tension, worry, intrusive thoughts, sense of inadequacy). Our finding of a present-absent-anxiety dichotomy is in line with results reported in previous investigations [20, 39]. This is, however, the first study on older subjects in which an additional factor, related to performance anxiety, was found (see Table 3).

As for the normative data, we found no effect of sex, age, or education either on S-Anxiety or on T-Anxiety scores. Therefore, we provided unadjusted cutoffs for both scales, one promoting higher specificity, and the other higher sensitivity. The choice of the reference cutoff should be guided by the aims of the assessment. For instance, experimental settings typically pose anxiety as an exclusion criterion; therefore, the cutoff fixed at the 95th centile should be preferred as it guarantees higher specificity, and hence fewer false positives. In the clinical settings, where decreasing the risk of false negatives is imperative, the cutoff fixed at the 90th centile should be preferred as it guarantees higher sensitivity.

With respect to age, in earlier studies, T-Anxiety scores were found to increase with age [40], while S-Anxiety scores were found to decrease with age [19]. However, there are studies in which age did not affect either T-Anxiety [18, 20, 21, 41] or S-Anxiety scores [20, 41]. These sparse and mixed findings make unclear whether anxiety shows stable or variable patterns in late life, and whether changes across old ages-if any-are towards higher or lower anxiety. One might theoretically expect that as risk factors for negative affect are highly prevalent among the elderly, anxiety should increase while aging proceeds. Furthermore, aging is associated with abnormal structural connectivity between the ventral prefrontal cortex and amygdala [42]. This may decrease the frontal regulatory control over the amygdala [43], thus determining more anxiety symptoms in the elderly. Nevertheless, if one focuses on the broader literature linking emotional functioning and aging, an age-related upward trajectory should be expected, with emotional maturation enhancing as a function of age [44].

As concerns the effect of education on the STAI-Y, results of earlier studies showed inconsistencies. Some studies reported higher T-Anxiety [20, 45] and S-Anxiety [19, 20] in less educated elderly, while other studies found equivalent T-Anxiety across educational levels [18]. Anyhow, education is known to enable people to preserve mental resources, that, in turn, may boost higher resilience in regard to strain or stresses, hence protecting against anxiety [46].

Finally, even the effect of sex on the STAI-Y appears controversial. In earlier studies, S-Anxiety [19] and T-Anxiety scores $[18,21]$ were found to be higher in old women as compared to men; yet, old males and females were found to have equivalent scores on both the T-Anxiety and S-Anxiety scales [20]. However, it should be noted that women of all ages seem to be more at risk of developing anxiety as compared to men [47].

To better evaluate the contribution of our results, it is important to highlight the weaknesses of this study. Our sample has a limited size, and it includes only subjects residing in the Campania region. This might be considered a threat to the external/population validity of the study. However, our sample is representative of the Italian elderly population, as portrayed by the Italian National Institute of Statistics [48]. Furthermore, it includes a trifling number of individuals over eighty years of age; this may have hampered the possibility to disclose a non-linear relationship [45] between age and anxiety within the upper limit of the age distribution. In the face of these limitations, our data still represent a point where to start from to improve measurement and monitoring of anxiety in the Italian elderly population, thereby ensuring accurate and timely treatments of latelife anxiety. Any development in that direction will certainly improve both personal and public health, even more so in view of the psychological repercussions of the COVID-19 outbreak [49].

Supplementary Information The online version contains supplementary material available at https://doi.org/10.1007/s40520-021-01815-0.

Funding No funding was received for conducting this study.

\section{Compliance with ethical standards}

Conflict of interest On behalf of all authors, the corresponding author states that there is no conflict of interest.

Ethics approval The study was approved by the Suor Orsola Benincasa University Ethics Committee and performed in accordance with the ethical standards as laid down in the 1964 Declaration of Helsinki and its later amendments. 
Informed consent Written informed consent was obtained from all individual participants included in the study.

\section{References}

1. Yochim BP, Mueller AE, Segal DL (2013) Late life anxiety is associated with decreased memory and executive functioning in community dwelling older adults. J Anxiety Disord 27:567-575

2. Bryant C, Jackson H, Ames D (2008) The prevalence of anxiety in older adults: methodological issues and a review of the literature. J Affect Disord 109:233-250

3. Ilardi A, Caruso G, Ilardi CR et al (2020) Chest pain management: use of troponins in internal medicine wards. Diagnosis (Berl). https://doi.org/10.1515/dx-2020-0133

4. Roest AM, Zuidersma M, De Jonge P (2012) Myocardial infarction and generalised anxiety disorder: 10-year follow-up. Br J Psychiatry 200:324-329

5. Wolitzky-Taylor KB, Castriotta N, Lenze EJ et al (2010) Anxiety disorders in older adults: a comprehensive review. Depress Anxiety 27:190-211

6. Pietrzak RH, Maruff P, Woodward M et al (2012) Mild worry symptoms predict decline in learning and memory in healthy older adults: a 2-year prospective cohort study. Am J Geriatr Psychiatry 20:266-275

7. Maggi G, D'Iorio A, Di Meglio D et al (2020) The role of the motor subtypes on the relationship between anxiety and cognitive dysfunctions in Parkinson's disease. J Neural Transm (Vienna) 127:893-898

8. Santabárbara J, Villagrasa B, López-Antón R et al (2019) Clinically relevant anxiety and risk of Alzheimer's disease in an elderly community sample: 4.5 years of follow-up. J Affect Disord 250:16-20

9. Rosenberg PB, Mielke MM, Appleby BS et al (2013) The association of neuropsychiatric symptoms in MCI with incident dementia and Alzheimer disease. Am J Geriatr Psychiatry 21:685-695

10. Eysenck MW (1992) Anxiety: the cognitive perspective. Lawrence Erlbaum Associates, Hove

11. Eysenck MW, Derakshan N (2011) New perspectives in attentional control theory. Pers Individ Differ 50:955-960

12. Beaudreau SA, O'Hara R (2009) The association of anxiety and depressive symptoms with cognitive performance in communitydwelling older adults. Psychol Aging 24:507-512

13. de Vito A, Calamia M, Greening S et al (2019) The association of anxiety, depression, and worry symptoms on cognitive performance in older adults. Aging Neuropsychol Cogn B Aging Neuropsychol Cogn 26:161-173

14. Tales A, Basoudan N (2016) Anxiety in old age and dementiaimplications for clinical and research practice. Neuropsychiatry 6:142-148. https://doi.org/10.4172/Neuropsychiatry.1000133

15. Spielberger CD, Gorsuch RL, Lushene RE et al (1983) State-Trait Anxiety Inventory for adults: manual, instrument and scoring guide. Mind Garden, Palo Alto

16. Beck AT, Epstein N, Brown G et al (1988) An inventory for measuring clinical anxiety: psychometric properties. J Consult Clin Psychol 56:893-897

17. Taylor JA (1953) A personality scale of manifest anxiety. J Abnorm Psychol 48:285-290

18. Bergua V, Meillon C, Potvin O et al (2012) The STAI-Y trait scale: psychometric properties and normative data from a large population-based study of elderly people. Int Psychogeriatr $24: 1163-1171$
19. Potvin O, Bergua V, Meillon C et al (2011) Norms and associated factors of the STAI-Y State anxiety inventory in older adults: results from the PAQUID study. Int Psychogeriatrics 23:869-879

20. Bouchard S, Ivers H, Gauthier JG et al (1998) Psychometric properties of the French version of the State-Trait Anxiety Inventory (form Y) adapted for older adults. Can J Aging 17:440-453. https://doi.org/10.1017/S0714980800012708

21. Fuentes K, Cox B (2000) Assessment of anxiety in older adults: a community-based survey and comparison with younger adults. Behav Res Ther 38:297-309

22. Therrien Z, Hunsley J (2012) Assessment of anxiety in older adults: a systematic review of commonly used measures. Aging Ment Health 16:1-16

23. Dennis RE, Boddington SJ, Funnell NJ (2007) Self-report measures of anxiety: are they suitable for older adults? Aging Ment Health 11:668-677

24. Balsamo M, Cataldi F, Carlucci L et al (2018) Assessment of anxiety in older adults: a review of self-report measures. Clin Interv Aging 13:573-593

25. Folstein MF, Folstein SE, McHugh PR (1975) "Mini-mental state". A practical method for grading the cognitive state of patients for the clinician. J Psychiatr Res 12:189-198

26. Yesavage JA, Brink TL, Rose TL et al (1982) Development and validation of a geriatric depression screening scale: a preliminary report. J Psychiatr Res 17:37-49

27. Pedrabissi L, Santinello M (1989) Inventario per l'ansia di «Stato» e di «Tratto»: nuova versione italiana dello STAI Forma Y: Manuale. Organizzazioni Speciali, Firenze

28. Garofalo E, Iavarone A, Chieffi S et al (2020) Italian version of the Starkstein Apathy Scale (SAS-I) and a shortened version (SAS-6) to assess "pure apathy" symptoms: normative study on 392 individuals. Neurol Sci. https://doi.org/10.1007/s10072-020-04631-y

29. Spinnler H, Tognoni G (1987) Standardizzazione e Taratura Italiana di Test Neuropsicologici. Ital J Neurol Sci 1:8-120

30. De Vaus D (2004) Surveys in social research. Routledge, London

31. Kaiser HF (1960) The application of electronic computers to factor analysis. Educ Psychol Meas 20:141-151. https://doi.org/10. $1177 / 001316446002000116$

32. Cattell RB, Vogelmann S (1977) A comprehensive trial of the scree and $\mathrm{kg}$ criteria for determining the number of factors. Multivar Behav Res 12:289-325

33. Crawford JR, Garthwaite PH (2008) On the "optimal" size for normative samples in neuropsychology: capturing the uncertainty when normative data are used to quantify the standing of a neuropsychological test score. Child Neuropsychol 14:99-117

34. Marcoulides GA, Hershberger SL (1997) Multivariate statistical methods: a first course. Lawrence Erlbaum Associates, New Jersey

35. Zbozinek TD, Rose RD, Wolitzky-Taylor KB et al (2012) Diagnostic overlap of generalized anxiety disorder and major depressive disorder in a primary care sample. Depress Anxiety 29:1065-1071

36. Jenkins PE, Ducker I, Gooding R et al (2020) Anxiety and depression in a sample of UK college students: a study of prevalence, comorbidity, and quality of life. J Am Coll Health. https://doi.org/ 10.1080/07448481.2019.1709474

37. Cassidy EL, Lauderdale S, Sheikh JI (2005) Mixed anxiety and depression in older adults: clinical characteristics and management. J Geriatr Psychiatry Neurol 18:83-88

38. Kalin NH (2020) The critical relationship between anxiety and depression. Am J Psychiatry 177:365-367

39. Vagg PR, Spielberger CD, O'Hearn TP (1980) Is the state-trait anxiety inventory multidimensional? Pers Individ Differ 1:207214. https://doi.org/10.1016/0191-8869(80)90052-5

40. Himmelfarb S, Murrell SA (1984) The prevalence and correlates of anxiety symptoms in older adults. J Psychol 116:159-167 
41. Kvaal K, Laake K, Engedal K (2001) Psychometric properties of the state part of the Spielberger State-Trait Anxiety Inventory (STAI) in geriatric patients. Int J Geriatr Psychiatry 16:980-986

42. Davis SW, Dennis NA, Buchler NG et al (2009) Assessing the effects of age on long white matter tracts using diffusion tensor tractography. Neuroimage 46:530-541

43. Bishop SJ (2008) Neural mechanisms underlying selective attention to threat. Ann N Y Acad Sci 1129:141-152

44. Carstensen LL (1993) Motivation for social contact across the life span: a theory of socioemotional selectivity. In: Jacobs JE (ed) Nebraska symposium on motivation, vol 40. Developmental perspectives on motivation. University of Nebraska Press, Lincoln, pp 209-254

45. Teachman BA (2006) Aging and negative affect: the rise and fall and rise of anxiety and depression symptoms. Psychol Aging 21:201-207

46. Mirowsky J, Ross CE (1998) Education, personal control, lifestyle and health: a human capital hypothesis. Res Aging 20:415-449. https://doi.org/10.1177/0164027598204003
47. Boehlen FH, Herzog W, Schellberg D et al (2020) Gender-specific predictors of generalized anxiety disorder symptoms in older adults: results of a large population-based study. J Affect Disord 262:174-181

48. ISTAT (2011) General Population and Housing Census. Italian National Institute of Statistics. http://dati-censimentopopolazione. istat.it/Index.aspx. Accessed 10 Oct 2020

49. Sepúlveda-Loyola W, Rodríguez-Sánchez I, Pérez-Rodríguez P et al (2020) Impact of social isolation due to COVID-19 on health in older people: mental and physical effects and recommendations. J Nutr Health Aging. https://doi.org/10.1007/s12603-020-1469-2

Publisher's Note Springer Nature remains neutral with regard to jurisdictional claims in published maps and institutional affiliations. 